\title{
Effectiveness of Social Media in Road Traffic Congestion Management in Cities
}

\author{
Patrick N. Kiratu ${ }^{1}$, David Nzuki ${ }^{2}$ \\ Kenyatta University - Nairobi, Kenya
}

\begin{abstract}
Traffic congestion is common in major cities negatively impacting countries' economies. Conventional traffic control methods are unresponsive to emergent situations on the roads. Social media has become an integral part of peoples' lives in solving problems. This paper assesses its influence in traffic congestion management in cities. Four determinants are identified namely: users expected gain in status; obligation to others; unselfishness and direct compensation. The study found that social media usage positively influence road traffic management. Users derive satisfaction from active participation and selflessness. Social platforms unite users in a communication network where up-to-date traffic congestion information is propagated rapidly.
\end{abstract}

Keywords: Traffic congestion, Social media, Traffic management, Communication network, users participation

\section{Introduction}

Major cities all over the world face traffic congestion as the quest for personalized means of transport that is independent and comfortable increases. As a result, there are negative effects on countries' economies by lowering their national gross domestic product. This is due to cost of fuel and time wasted in traffic jams. In addition, there are risks associated with gridlocks such as car break-ins, snatching of valuable items and other social evils. According to [4], the world loses approximately five billion hours and two billion gallons of fuel annually in congestion delays. Other effects of traffic congestion include: hampering emergency services - such as police and medical services and increase in vehicle crashes as motorists rush to avoid being caught in gridlock. According to [19], road congestion is mainly due to increase in number of vehicles, poor transport planning and management, deficient public transport, shortage in road infrastructure and lack of road maintenance. But more importantly, inadequate traffic management measures also contribute to traffic jams. These measures would provide real-time, actionable information on the status of roads and relay the same to all the users thus ensuring smooth flow of traffic.

[4] identified two types of traffic congestion: recurrent and non - recurrent. Recurrent phenomenon is experienced when large numbers of vehicles use the limited space of the road network simultaneously during peak hours on daily basis. Non- recurrent congestions are as a result of random and often unplanned events such as traffic accidents, adverse weather conditions, vehicle breakdowns and some special events like holiday celebrations among others. Management of recurrent traffic is compounded by non-recurrent events and vice-versa. Consequently, traditional methods of traffic control - like traffic lights, are not receptive to various situations that can emerge on the roads, at any given time, adversely affecting smooth flow of traffic. Depending upon the prevailing circumstances, it is desirable that traffic flow be controlled and managed as per the current situation under the control and supervision of onsite traffic officer [12]. corroborated by research. In addition, it is able to combine text data with picture or video providing a better explanation of the prevailing situation. Hence its influence in decongesting cities or in reducing the impact of traffic congestion should be analyzed with a view to inform policy decisions and enable replication in other areas experiencing similar crisis.

\subsection{Problem Statement}

Social media is defined by [9] as a group of Internet-based applications built on the ideological and technological foundations of Web 2.0, and that allow the creation and exchange of user-generated content. It encompasses collaborative platforms like Wikipedia, blogs, micro-blogs (e.g. Twitter, Integra, WhatsApp), content communities (e.g. YouTube) social networking sites (e.g. Facebook) virtual game worlds (e.g. The Sims) and virtual social worlds (e.g. Habbo) [9].

Emergence of social media has led to more people opting to communicate and exchanging ideas, suggestions or complaints online. These technologies support text, pictures, sound and video making them better suited to explain reallife occurrences like traffic congestion. Several topics get discussed through social media ranging from gossip, entertainment, general information, news among others. Priority of topics is determined by the number of users contributing to it and the persistence of the issue being canvassed. Issues that cause constant irritation such as, runaway corruption, harassment by law enforcement agencies, politics, adverse weather, emergencies, entertainment and traffic jam tend to stir a lot of discussion online.

Use of social media information during road traffic crises has been advanced by [23] due to its robustness and flexibility compared to conventional methods. This is corroborated by [4] who argued that social media information enable fast and more accurate traffic congestion information to be reach road users.

Social media has become an essential part of peoples' lives. Its ability to provide factual, real-time information has been 


\section{International Journal of Science and Research (IJSR) \\ ISSN (Online): 2319-7064}

Index Copernicus Value (2015): 78.96 | Impact Factor (2015): 6.391

\subsection{Objectives of the Study}

The general objective of this study is to investigate the influence of social media in road traffic management in cities and in particular to:

1) To determine whether participation in social media positively influences road traffic congestion management in cities;

2) To determine whether anticipated reciprocity in social media positively influence road traffic management in cities;

3) To determine whether unselfishness in social media positively influence road traffic management in cities; and

4) To determine whether direct reward in social media positively influence road traffic management in cities.

\section{Theoretical Framework}

This study is based on social exchange theory proposed by [8] to explain the influence of social media in road traffic congestion management. The theory developed out of combination of ecology, psychology and sociology studies exploring exchange between individuals or small groups. It employs a cost- benefit formation and the comparison of alternatives to explain how human beings communicate with each other, how they form relationships and bonds and how social groups are formed through communication exchanges [17]. The author summarized reasons why people engage in social exchange as follows:

- Expected gain in reputation and influence on others;

- A predictable response on the part of others;

- Unselfishness; and

- Direct reward.

The theory recognizes mutual commitment of the parties involved in social networks that result in an imbalance of obligations when violated. This imbalance leads to status differences which must be balanced off by the defaulting party. According to [2], the obligations give-and-take scenario repeatedly occurs in social exchange groups. This is important in ensuring that individuals in a social network participate in discussions make them appropriate in addressing relentless issues. It is at the implied equilibrium level of social exchange that the real benefits of social media are realized and its applicability in solving real-life situations, such as solving traffic congestion, are enhanced.

According to this theory, communication between actors in a social network generates a form of interdependence among the users where they strive to adjust to each other's expectations. [5] argued that, there exists a form of 'power'that could be used to explain the relation of the actors. In social media, group members are closely-knitted together forming a large network, where commitment to group activities online can be explained by power or influence dynamics of the other members where a user derives most satisfaction.

Information is propagated in social networks through users, who forward it to other group members in the same or different platform. Being active rather than passive was proposed by [16] to be a key determinant in social media exchange. According to [6], influential social network users played a critical role in extracting traffic data from twitter responses. Social media reputation and influence on others is, hence, based on how active a user is in contributing to issues and the number of people actively involved in the discussion, popularly known as followers. In some social media platforms like WhatsApp, the influential user- also known as the administrator, creates the other users' accounts forming a large network of friends, work mates, acquaintances, relatives, neighbors and so on. It is possible for an individual to belong to multiple social media groups either in the same platform or in multiple platforms and actively contributing to the issues canvassed in all. Such individual are critical in propagating communication to a wider audience, making these media robust in providing solutions to real-life situations involving many people like traffic congestion.

Social media is a more flexible mode of communication, especially in situations where users are time constrained and lacks necessary comfort to compose comprehensive messages, like in traffic jam or emergencies. In addition, it also allows user to seek clarifications and updates from others as frequently as the situation persists. This was confirmed by [6], in a study on tweeter social network who found that users were tweeting and retweeting traffic congestion updates. This is replicated in the other types of social networks where users engage in a conversation and keep posting updates as long until the issue is resolved. Social media information exchanged among the users should be accurate in order to nurture trust among them and inform decision making. Trust refers to a bi-directional bond between two entities - such as users of the same social group, which compels them exchange only relevant and reliable information [3].

In a social exchange, [8] argued that individual contributions to issues may be viewed as a form of cost and responses by others as a reward. According to this theory, social recognition is preferable to social gratitude and as benefits (difference between cost and reward) of social exchange continue to increase, usage behavior tends to stabilize. However, this is contradicted by [14] who viewed participation in social media as voluntary and, therefore, not subject to compensation. Similarly, this was countered by [13] who proposed a game-based application to reward social media users with the highest participation index based on accurate traffic congestion comments made. Likewise, [4] recommended a reward system in form of ranking based on service quality differentiation, to encourage social media users to report accidents and unusual occurrences on the roads. Torn between these discrepancies in literature, this study adopted direct reward as suggested by the theory to explain why people engage in social exchange. Traffic management information is critical in de-congesting cities hence any form of reward as a means of increasing accurate user responses for these purpose is viewed appropriate.

\section{Discussion}

Studies on effects of social media in problem solving suggest increased usage in varied areas. In a study, [22] reported a positive influence between social media usage 


\section{International Journal of Science and Research (IJSR) \\ ISSN (Online): 2319-7064}

Index Copernicus Value (2015): 78.96 | Impact Factor (2015): 6.391

and quest for e-learning. Similarly, [10] found that use and commitment to social media positively influenced the social and information aspects of a user, which in turn influenced adoption of e-commerce. On the other hand, [11] argued that social media could help bridge the communication gap between customers and hotels faced with a health crisis of bedbug infestations. The medium could be used to mitigate losses that could emanate from poorly managing the crisis such as: economic loss, reputational damages, negative comments, complaints and lawsuits.

Previous researches on use of social media in road traffic management have paid little attention to the influence aspect. In fact, majority of them have studied only one platform and completely ignored the others. Different categories of social media have different implementations and run on different platforms. Some run on mobile devices only like WhatsApp, while others run on both mobile devices and computers like Twitter and Facebook. According to [18], the two most popular platforms, based on the number of active users enrolled worldwide are Facebook and WhatsApp. Majority of the researchers have based their work on Twitter yet it is not the most popular platform. In addition, societies in different countries have different preferences for social media platform. It is for this reason that this study intends to determine the influence of social media on road traffic management in cities across the platforms to fill in this gap.

In another study, [13] proposed a game-based design of social media-based digital network system where public could be involved in the collection and validation of traffic data in Indonesia. This study failed to recognize that social media conversations take place directly within social groups and not collected for analysis purposes. Reward mostly takes place within the groups and not externally as the authors suggested. On the other hand, [1] argued that social media data, like tweets, could not be used directly to explain road traffic condition due to their unstructured nature and raw language used. They argued that such data would be difficult to process using a computer and recommended a natural language processing approach to summarize traffic information from Twitter before disseminating to the users. Likewise, the authors ignored social groupings as a predominant mode of exchange in social groups where actionable information regarding road congestion is executed. The study is also based on a weak model anchored on language since there is a standard, predictable response expected of users in a social group. In addition, the selflessness nature of contributions in social media implies that they are of standards that bear most benefits to the users, notwithstanding language use.

In another study, [3] proposed a road traffic management mathematical model that combined a language model and a statistical model to identify traffic congestion locations based on tweeter data. Once again, the study was inconclusive in that the model was not tested with other types of social media. On the other hand [20], proposed a traffic estimation method in cities based on combined data from user tweets and their geographical positioning system. However, social media conversations were found not to essentially follow a strict linear correlation with the volume of traffic jam in order to be subjected to elaborate mathematical models by [7].

On the other hand, [6] proposed a social media - based transport control model affixed on event detection with text synopsis from Twitter. Equally, the other authors did not apply the model to the other categories of social media and contextualize the results. Moreover, [4] took a broader view by surveying the existing traffic management systems and assessing their usage level in realizing smart city status. This approach grouped social media with other forms of traditional traffic management systems thereby diminishing their influence making it difficult to account for.

Social media was found to be beneficial in de-congesting cities compared to other forms of traffic management systems by [21], who observed that it was not limited by information sources and could accommodate various forms of data such as videos or pictures. Furthermore, it was more flexible and more appropriate to road emergency management and traffic dispersion. In a study on road congestion in China, [23] reported that Twitter user suggestions on traffic flow and conditions helped in decongesting cities during celebrations. As with the other studies, these one also failed to consider the influence of other social media platforms to such scenarios.

Besides, [7] proposed a model of explaining drivers' reactions on social media when caught in traffic jam during three shifts of the day: morning, noon and afternoon. They found no linear relationship between responses and the severity of the jam and suggested existence of underlying factors such as driver's emotional status. Although they claimed that the model was $38 \%$ better than linear approaches, they based their study on Twitter only. Their study was inconclusive because it zeroed in only on drivers stack in traffic jam and failed to recognize the contribution of passengers in those vehicles also caught in gridlock as well as pedestrians and other stakeholders affected by the situation on the road. This study proposes that the other social media platforms could also explain a significant percentage of the shortfall from tweeter conversations in road traffic de-congestion. This is confirmed by [3] who proposed an approach to traffic congestion monitoring where pedestrians, drivers, and passengers were viewed as human sensors and their tweets as explanation of nearby current traffic conditions.

The other social media platforms, though scantly studied, have also been used in road traffic management in cities. For instance, [15] reported that in India traffic police were able to guide motorists from messages and photos received from a WhatsApp helpline launched for public to report traffic jams and incidences on roads. YouTube a communication site where signed up users upload videos for public viewing has numerous tutorials on city traffic navigation, simulations and real data feeds on traffic jam management. Users leverage on incorporated video recorders in mobile devices to capture real traffic data and post it on the web immediately. This can be done while on the move or stationery in traffic congestion. On the other hand, bloggers engage their followers on road traffic management Likewise, virtual worlds and virtual social worlds have been

\section{Volume 6 Issue 1, January 2017




\section{International Journal of Science and Research (IJSR) \\ ISSN (Online): 2319-7064}

Index Copernicus Value (2015): 78.96 | Impact Factor (2015): 6.391

used to simulate traffic jam scenes and users' interactions and navigation can be applied in real-life situations to decongest cities. The widespread popularity of social media sites suggest that they are successful, accepted and applicable in personal, social, and professional lives of individual users and especially to city dwellers who share common problem of traffic jam.

\section{Conclusion}

This study has shown that social media has both intensive and extensive influence on road traffic management. In intensive influence, it is used to manage short-term and immediate occurrences such as blocked roads, accidents and other unexpected hindrances on the roads. In extensive influence, social media suggestions and opinions have been implemented in managing expected and recurrent road traffic congestion. Literature reviewed suggests that real life events, such as gridlock in cities, trigger social media discussion. Active participation in these discussions ensures that information is propagated in the network. Social networks are also linked with each other through individuals belonging to multiple groups and multiple platforms. However, there is little literature on the influence of other social media platforms in road traffic management especially Facebook - the most popular platform across the world. This is probably due to the fact that different countries seem to adopt different platforms. Positive influence of Tweeter in traffic management in cities has been proved by literature.

The basic elements of social networks are small groups where members derive most satisfaction. Users involvement in such networks positively influence road traffic management in cities since each member is indebted to each other in terms of contributing to the issues affecting the group. Deficiency in members' contribution obligation causes a disequilibrium which must be restored by active participation in discussion, thereby enhancing communication of actionable, relevant and current information capable of de-congesting cities.

The welfare of members in social media groupings has been found to be a critical characteristic in these networks. The nucleus of a social group is often an influential user, who initially invites and enrolls acquaintances, work-mates, neighbors and other persons of interest leading to a large network of exchanging ideas. Based on this genesis, there is trust among the users and the contributions to the conversations canvassed are largely philanthropic. Individuals derive reward by remaining and contributing to discussions in a social group. People who are engaged in interaction are rationally seeking to maximize profits by receiving approval and acknowledgement from the others.

\section{Recommendations}

Research on social media influence in road traffic decongestion have largely relied on data extraction, mining or summarization and proposing new models based on such findings. However, there is a lot of information exchanged directly and acted upon by members of a social group, whose effects is not accounted for in these studies hence the need for a study in this area. In addition, there is need to carry out a quantitative study on the influence of other social media platforms in de-congesting cities. Facebook, for instance, the most popular social network platform worldwide with over 900 million users, is scantly researched. Finally, there is need to study the popularity of different social media platforms in various countries, communities or social classes and provide reasons for the findings in order to adequately explain their influence in road traffic congestion management.

\section{References}

[1] Aziz, M. V., Prihatmanto, A. S., Henriyan, D., \& Wijaya, R. (2015). Design and Implementation of Natural Language Processing with Syntax and Semantic Analysis for Extract Traffic Conditions from Social Media Data. In IEEE 5th International Conference on System Engineering and Technology (pp. pp. 43-48). UiTM Shah Alam Malaysia: IEEE.

[2] Blau, P. M. (1964). Exchange and Power in Social Life. Transaction Publishers, pp. 352.

[3] Chen, P.-T., Chen, F., \& Qian, Z. (2014). Road Traffic Congestion Monitoring in Social Media with HingeLoss Markov Random Fields. In 2014 IEEE International Conference on Data Mining (pp. pp. 80 89). IEEE.

[4] Djahel, S. e. (2015). A Communications-Oriented Perspective on Traffic Management Systems for Smart Cities: Challenges and Innovative Approaches. IEEE Communication Surveys and Tutorials, vol. 17, no.1, pp. 125-151.

[5] Emerson, R. M. (1962). Power-Dependence Relations. American Sociological Review, vol. 27, no. 1 , pp. 3141.

[6] Fu, K., Lu, C.-T., Nune, R., \& Tao, J. X. (2015). Steds: Social Media based Transportation Event Detection with Text Summarization. In 2015 IEEE 18th International Conference on Intelligent Transportation Systems (pp. pp. 1952-1957). IEEE.

[7] Georgiou, T., Abbadi, A. E., Yan, X., \& George, J. (2015). Mining Complaints for Traffic-Jam Estimation: A Social Sensor Application. In 2015 IEEE/ACM International Conference on Advances in Social Networks Analysis and Mining (pp. pp. 330-335). Paris, France: IEEE.

[8] Homans, G. C. (1958). Social Behavior as Exchange. American Journal of Sociology, vol. 63, no. 6 , pp. 597606.

[9] Kaplan, A. M., \& Haenlein, M. (2012). Social media: back to the roots and back to the future. Journal of Systems and Information Technology, vol. 14, no. 2 , pp. 101-104.

[10]Kwahk, K.-Y., \& Ge, X. (2012). The Effects of Social Media on E-commerce: A Perspective of Social Impact Theory. In 45th Hawaii International Conference on System Sciences (pp. pp. 1814-1823). Hawaii: IEEE Computer Society.

[11]Liu, B. e. (2010). Using social media in hotel crisis management: the case of bed bugs. Journal of Hospitality and Tourism Technology, vol. 6, no. 2 , pp. $102-112$.

\section{Volume 6 Issue 1, January 2017}




\section{International Journal of Science and Research (IJSR) \\ ISSN (Online): 2319-7064 \\ Index Copernicus Value (2015): 78.96 | Impact Factor (2015): 6.391}

[12] Misbahuddin, S., Zubairi, J. A., Saggaf, A., Basuni, J., A-Wadany, S., \& Al-Sofi, A. (2015). IoT Based Dynamic Road Traffic Management for Smart Cities. In 2015 12th International Conference on High - Capacity Optical Network and Enabling/Emerging Technologies (HONET) (pp. pp. 1-5). IEEE.

[13] Mulyana, A., Hindersah, H., \& Prihatmanto, A. S. (2015). Gamification Design of Traffic Data Collection Through Social Reporting. In 4th International Conference on Interactive Digital Media (ICIDM) (pp. pp. 1-4). Bandung - Indonesia: IEEE.

[14]Pan, B., \& Crotts, J. C. (2012). Theoretical Models of Social Media, Marketing Implications, and Future Research Directions. Social Media in Travel, Tourism and Hospitality, vol. 46 , pp. 73-83.

[15] Rejiv, K. (2015, November 27th). Caught in a traffic jam? Message or WhatsApp 7259100100. Retrieved November 11th, 2016, from The Times of India: http://timesofindia.indiatimes.com/city/bengaluru/Caug ht-in-a-traffic-jam-Message-or-WhatsApp7259100100/articleshow/49947

[16] Romero, D. M., Galuba, W., Asur, S., \& Huberman, B. A. (2011). Influence and Passivity in Social Media. In Joint European Conference on Machine Learning and Knowledge Discovery in Databases (pp. pp. 18-33). Berlin: Springer Heidelberg.

[17] Sáez-Martín, A. e. (2016). A vision of social media in the Spanish smartest cities. Transforming Government: People, Process and Policy, vol. 8, no. 4 , pp. 521 - 544.

[18] Statista. (2016, November 6th). Global social media ranking 2016/Statistic. Retrieved November 6th, 2016, from Most famous social network sites 2016, by active users: https://www.statista.com/statistics/272014/globalsocial-networks-ranked-by-number-of-users/

[19]UNEP. (2013). Towards Sustainable Transport in SubSaharan Africa. Nairobi: UNEP.

[20] Wang, S. e. (2016). Estimating Urban Traffic Congestion with Multi-sourced Data. In 17th IEEE International Conference on Mobile Data Management (pp. pp. 82-91). Chicago: IEEE Computer Society.

[21] Wang, X., He, L., Stenneth, L., Yu, P. S., Zhoujun, L., \& Huang, Z. (2013). Traffic Congestion and Social Media in China. IEEE Intelligent Systems, vol. 28, no. 1 , pp. 72-77.

[22] Xanthidis, D., \& Alali, A. S. (2014). Effects of Social Media on eLearning development in the Gcc. In Computer Applications \& Research (WSCAR), 2014 World Symposium on, Sousse (pp. pp. 1-6). Riyadh, Saudi Arabi: IEEE.

Zeng, K., Liu, W., Wang, X., \& Chen, S. (2013). Traffic Congestion and Social Media in China. IEEE Intelligent Transport Systems, vol.1, no. 28 , pp. 72-77. 